\title{
Perancangan Aplikasi Multimedia Obyek Wisata Sulawesi Tenggara
}

\author{
Rahmat Inggi \\ rahmatinggi35@gmail.com \\ Sistem Informasi, STMIK Bina Bangsa Kendari
}

\begin{abstract}
Abstrak
Provinsi Sulawesi Tenggara merupakan provinsi yang cukup terkenal dengan keindahan alam dan pemandangannya. Maka tak mengherankan jika banyak sekali wisatawan yang selalu datang ke Provinsi yang satu ini. selain bisa menikmati wisata alamnya yang sangat cantik dan indah. Kita juga bisa menikmati berbagai macam wisata budaya dan wisata sejarah yang sangat menarik di kunjungi, Akantetapi sulit untuk wisatawan memilih wisata apa yang sangat indah untuk di kunjugi diakibatkan kurangnya informasi mengenai wisata yang berada disulawesi tenggara. Dengan adanya Aplikasi Multimedia obyek wisata Sulawesi tenggara, akan sangat berguna sekali bagi para wisatawan yang ingin berlibur dapat memanfaatkan media komputer untuk mendapatkan informasinya mengenai informasi wisata yang berada di Provinsi Sulawesi Tenggara.
\end{abstract}

Kata kunci: Perancangan, Aplikasi, Multimedia, Wisata

\begin{abstract}
Southeast Sulawesi province is a province that is quite famous for its natural beauty and scenery. So it is not surprising that there are so many tourists who always come to this one province. besides being able to enjoy natural tourism which is very beautiful and beautiful. We can also enjoy various kinds of cultural and historical tours which are very interesting to visit. However, it is difficult for tourists to choose what tours are very beautiful to visit due to a lack of information about tourism in Southeast Sulawesi. With the existence of the Southeast Sulawesi tourism object multimedia application, it will be very useful for tourists who want to take a vacation can use computer media to get information about tourist information in Southeast Sulawesi Province.
\end{abstract}

Keyword : Design, Applications, Multimedia, Travel

\section{Pendahuluan}

Perkembangan dunia pariwisata di Indonesia sudah semakin banyak, bukan saja menawarkan obyek-obyek wisatanya tetapi menawarkan keindahan alam lainnya, misalnya saja obyek wisata pantai yang sangat menarik untuk dikunjungi, salah satunya adalah Sulawesi Tenggara yang terletak di tenggara Pulau Sulawesi. Provinsi Sulawesi Tenggara memang cukup terkenal dengan keindahan alam dan pemandangannya. Maka tak mengherankan jika banyak sekali wisatawan yang selalu datang ke Provinsi yang satu ini. selain bisa menikmati wisata alamnya yang sangat cantik dan indah. Kita juga bisa menikmati berbagai macam wisata budaya dan wisata sejarah yang sangat menarik di kunjungi.

Walaupun Sulawesi Tenggara merupakan tempat yang menarik untuk dikunjungi, tetapi letak dan wilayah keberadaannya belum banyak orang yang mengetahuinya. Padahal Sulawesi Tenggara menyajikan panorama alam yang indah dan juga sebagai kawasan wisata pantai yang menarik untuk wisatawan, baik untuk wisatawan lokal maupun mancanegara.

Mungkin dengan adanya Multimedia obyek wisata Sulawesi tenggara, akan sangat berguna sekali bagi para wisatawan yang ingin berlibur dapat memanfaatkan media komputer 
Jurnal Sistem Informasi dan Sistem Komputer, Vol. 5, No. 2, Juli 2020

pISSN: 2581-1614 eISSN: 2715-906X

untuk mendapatkan informasinya mengenai informasi wisata yang berada di Provinsi Sulawesi Tenggara.

Oleh karena informasi mengenai wisata provinsi Sulawesi tenggara masih sangat kurang sekali, maka penulis akan mencoba merancan suatau program aplikasi Multimedia Obyek Wisata Sulawes Tenggara sehingga dapat memudahkan pengunjung untuk melihat dan mengetahua objek-objek wisata apa saja yang ada di Sulawesi tenggara.

\section{Landasan Teori}

\subsection{Pengertian Sistem}

Dalam suatu organisasi, informasi adalah sesuatu yang sangat penting di dalam proses pengambilan keputusan oleh pihak managemen. Kini bidang dalam pengolahan informasi adalah sistem-sistem yang memberikan sumber-sumber informasi dalam mendukung fungsi managerial dan pengambilan keputusan. Sistem tersebut secara umum disebut sistem informasi managemen, adapun pengertian sistem menurut para ilmuan, diantaranya adalah: Menurut Jerry Fit Gerald, menyatakan bahwa "Sistem adalah suatu jaringan kerja dari prosedur-prosedur yang saling berhubungan, berkumpul bersama-sama untuk menyelesaikan suatu sasaran yang tertentu". [1]

Sedangkan adapula pendapat lain yang mengemukakan bahwa "Sistem adalah kumpulan elemen-elemen yang saling berkaitan dan bertanggung jawab memperoses input sehingga menghasilkan output". [2]

\subsection{Pengertian Informasi}

Sedangkan pengertian "Informasi adalah data yang telah diolah menjadi sebuah bentuk yang berarti bagi penerimannya dan bermanfaat bagi pengambilan keputusan saat ini atau mendatang”. [2]

Informasi dapat diperoleh dari sistem informasi, dimana menurut Robert A. Leitch dan K. Roscoe Davis, "Sistem informasi adalah suatui sisitem di dalam suatu organisasi yang mempertemukan kebutuhan pengolahan transaksi harian, mendukung operasi, bersipat manajerial dan kegiatan strategi dari suatu organisasi dan menyediakan pihak luar tertentu dengan laporan-laporan yang diperlukan”. [1]

\subsection{Pengertian Aplikasi}

Dalam bahasa komputernya aplikasi adalah program komputer yang dibuat untuk menolong manusia melaksanakan tugas tertentu" [6]

Aplikasi software yang dirancang untuk penggunaan praktisi khusus, klasifikasi luas ini dapat dibagi menjadi dua.

a. Aplikasi software spesialis, program dengan dokumentasi tergabung yang dirancang untuk menjalankan tugas.

b. Aplikasi paket, suatu program dengan dokumentasi tergabung yang digunakan untuk sejenis masalah tertentu, misalnya penggajian (Payroll). 
Jurnal Sistem Informasi dan Sistem Komputer, Vol. 5, No. 2, Juli 2020

pISSN: 2581-1614 eISSN: 2715-906X

\subsection{Pengertian Multimedia}

Multimedia adalah gabungan kata yang terdiri dari kata multi dan media. Multi berarti banyak atau lebih dari satu, sedangkan media berarti bentuk atau jenis sarana yang dipakai untuk menyampaikan informasi. Seperti yang telah dijelaskan, multimedia adalah kombinasi dari teks, gambar, suara, animasi dan video. Bila dalam suatu aplikasi multimedia pengguna/pemakai multimedia diberikan suatu kemampuan untuk mengontrol elemen-elemen yang ada, multimedia tersebut disebut dengan Interactive Multimedia. Dan apabila dalam aplikasi multimedia tersebut disediakan struktur dari elemen terhubung yang dapat dikendalikan oleh pengguna / pemakai. Semua pesan-pesan, perangkat lunak dan makna yang dipresentasikan oleh komputer atau layar televisi disebut multimedia project, sedangkan yang dipasarkan dalam kotak atau pembungkus khusus, dengan atau tanpa instruksi disebut multimedia title.

\subsection{Pemrograman Visual Basic}

Visual Basic adalah program penghasil aplikasi yang bekerja pada system operasi Windows, Dengan menggunakan Visual Basic kita tidak perlu bersusah payah menuliskan kode program, Karena intelligent IDE (Integrated Development Integration) atau tempat kita bekerja untuk menghasilkan program aplikasi akan aktif membantu, Misalnya, kita tidak perlu lagi mengingatingat syntak prosedur yang sering lupa, Autolist member dan Autoquick akan selalu menampilkan pilihan.”[4]

Memang harus diakui, jika dibandingkan dengan bahasa $\mathrm{C}++$, Visual Basic masih tertinggal dalam beberapa hal, namun dengan hadirnya versi terbaru, yaitu Visual Basic 6.0 yang kaya dengan fasilitas sehingga bisa mencukupi kebutuhan pemakai, maka ketinggalan dalam segi bahasa bisa dilunasi.

Kekuatan Visual Basic 6.0 dalam bidang database, sekarang lebih ditingkatkan dengan adanya ODBC (Open DataBase Conectivity), DAO (Data Access Object), ADO (Activex Data Object) maupun RDO (Remote Data Object). Dengan demikian kita bisa menyusun aplikasi database secara mudah dan menyenangkan, mulai dari desktop, client server sampai database.

\section{Metode}

\subsection{Objek Penelitian}

Penelitian ini dilakukan di dinas Pariwisata Provinsi Sulawesi Tenggara yang berada di Jl.Tebau Nunggu No.2 Kendari-Sulawesi Tenggara. Penelitian dilaksanakan mulai dari Maret 2020 sampai dengan Mei 2020.

\subsection{Jenis dan Metode Pengumpulan Data}

Dalam penelitian ini penulis menggunakan metode pengumpulan data berupa sumber data primer (observasi dan wawancara). Data primer merupakan sumber data yang diperoleh langsung dari sumber asli (tidak melalui media perantara). Data ini diperoleh dari kegiatan observasi yaitu melakukan pengamatan langsung pada objek penelitian, mengadakan wawancara dengan pihak yang terlibat dan menganalisis dokumen yang berhubungan dengan keperluan penelitian. 
Jurnal Sistem Informasi dan Sistem Komputer, Vol. 5, No. 2, Juli 2020

pISSN: 2581-1614 eISSN: 2715-906X

\subsection{Analisis Kebutuhan}

Hal pertama yang perlu dilakukan dalam analisa kebutuhan sistem adalah menentukan dan mengungkapkan kebutuhan sistem. Kebutuhan sistem terbagi menjadi dua yaitu, kebutuhan sistem fungsional dan kebutuhan sistem non fungsional, yang diperlukan untuk mencapai tujuan yang ingin dicapai.

\section{Analisis dan Pembahasan}

\subsection{Analisis Aplikasi}

Pembangunan yang berkesinambungan ternyata tidak dapat dicapai hanya dengan mengandalkan strategi pertumbuhan. Fakta yang ada, strategi itu ternyata hanya memperlebar kesenjangan, yang implikasi-implikasinya sama sekali tidak pernah dikehendaki. Untuk itu, diperlukan suatu perubahan structural dengan cara memperkuat kedudukan dan peran ekonomi kerakyatan. Perubahan yang meliputi proses perubahan dari ekonomi tradisional ke moderen, dari ekonomi lemah ke tangguh, dari subsisten kepasar dan dari ketergantungan kemandirian. Perubahan itu membutuhkan sejumlah persyaratan. Yakni, pengalokasian sumberdaya, penguatan kelembagaan, penguasaan teknologi serta pemberdayaan sumberdaya manusia. Berdasarkan dalam pencapaian perubahan dibidang teknologi terutama teknologi informasi, maka penulis ingin memperkenalkan wisata apa saja yang terdapat di Sulawesi Tenggara dalam bentuk aplikasi. Disini user dapat mengetahui obyek-obyek wisata yang terdapat di Sulawesi Tenggara melalui form aplikasi yang telah dibuat sebagai salah satu bentuk kekayaan Indonesia. Metode pencarian yang digunakan pada aplikasi ini berdasarkan kategori yang dipilih user kemudian ditampilkan obyek-obyek wisata apa saja yang terdapat didalamnya. Berhubung banyaknya pulau-pulau yang terdapat di Sulawesi tengara yaitu terdapat 15 Kabupaten dan 2 Kota, maka di aplikasi ini hanya akan di tampilkan beberapa kabupaten dan pulau saja berikut obyek wisatanya.

\subsection{Perancangan Program}

Pada perancangan program ini terdapat struktur menu, spesifikasi program, algoritma, perancangan input dan output program dan untuk metode penyimpanan datanya penulis mendesainnya dengan terstruktur agar mudah diikuti.

\subsubsection{Struktur Menu}

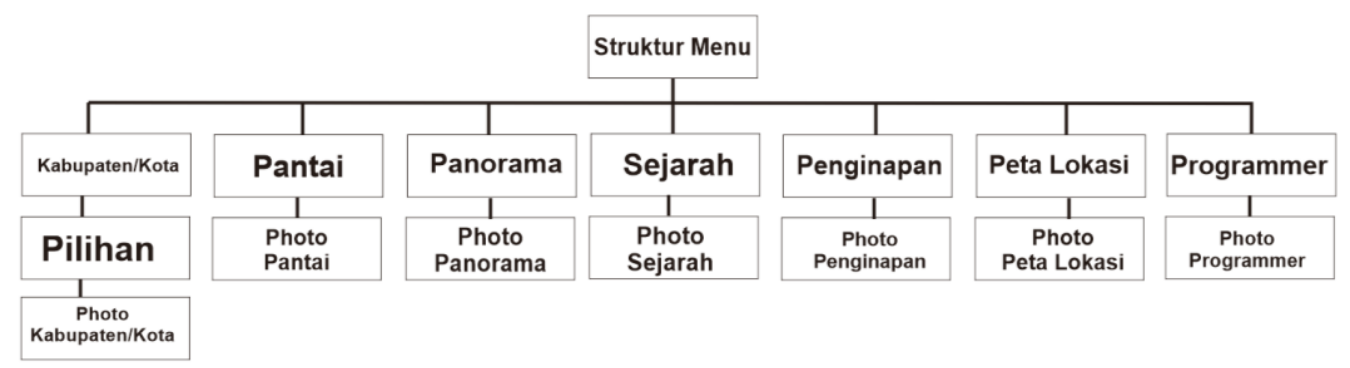

Gambar 1 : Struktur Menu 
Jurnal Sistem Informasi dan Sistem Komputer, Vol. 5, No. 2, Juli 2020

pISSN: 2581-1614 eISSN: 2715-906X

\subsubsection{Spesifikasi Program}

Berdasarkan struktur menu yang telah dibuat, maka pada Aplikasi Multimedia Wisata Sulawesi Tenggara adalah sebagai berikut :

Spesifikasi Program Menu Utama :

a. Nama : Menu Utama

b. Tujuan : Menampilkan menu pilihan pengolahan

c. Proses : Pulau : menampilkan menu pilihan namanama pulau

Panorama : menampilkan panorama

Pantai : menampilkan nama-nama pantai

Sejarah : : menampilkan sejarah Sulawesi Tenggara

Peta Lokasi : menampilkan peta lokasi Sulawesi Tenggara

Penginapan : menampilkan nama-nama penginapan

d. Flowchart :

Keluar $\quad$ : untuk keluar dari aplikasi tersebut

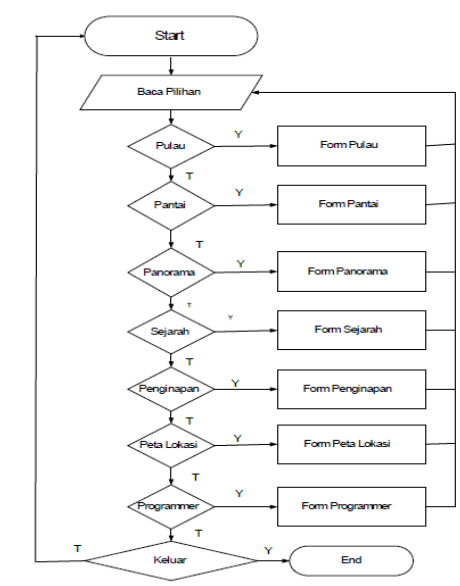

Gambar 2 : Flowchar Menu Utama

\subsubsection{Perancangan Tampilan Program Input Output}

Berikut adalah perancangan tampilan program yang telah dibuat oleh penulis untuk Aplikasi Multimedia Wisata Sulawesi Tenggara.

a. Rancangan Input Menu Utama

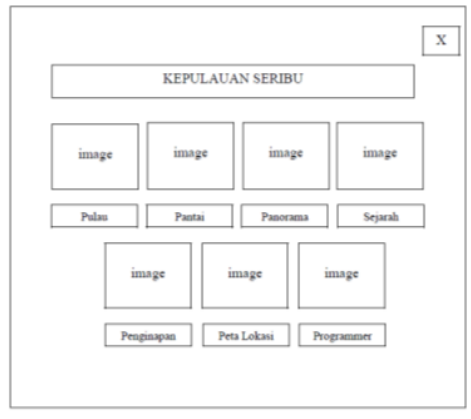

Gambar 3 : Rancangan Input Menu Utama 
Jurnal Sistem Informasi dan Sistem Komputer, Vol. 5, No. 2, Juli 2020

pISSN: 2581-1614 eISSN: 2715-906X

b. Rancangan Output Tampilan Kabupaten/Kota

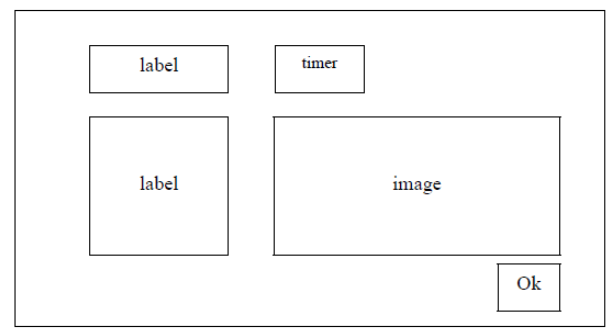

Gambar 4 : Rancangan Output Tampilan Kabupaten/Kota

\subsection{Algoritma}

\subsubsection{Algoritma Menu Utama}

a) Tampilkan Menu Utama

b) Baca Pilihan

c) Jika pilihan $=$ Kabupaten/Kota, maka masuk ke form pilihan nama-nama Kabupaten/Kota

d) Jika pilihan = Panorama, maka akan masuk ke form Panorama

e) Jika pilihan $=$ Pantai, maka akan masuk ke form Pantai

f) Jika pilihan $=$ Sejarah, maka akan masuk ke form sejarah

g) Jika pilihan = Peta Lokasi, maka akan masuk ke form peta lokasi

h) Jika pilihan = Penginapan, maka akan masuk ke form penginapan

i) Jika pilihan $=X$, maka selesai

\subsubsection{Algoritma Form Pilihan Nama-nama Kabupaten/Kota}

a) Tampilkan Menu pilihan Kabupaten/Kota

b) Baca Pilihan

c) Jika pilihan salah satu nama Kabupaten/Kota, maka masuk pada data-data Kabupaten/Kota

d) Jika pilihan kembali, maka kembali ke Menu Utama

\subsubsection{Algoritma Form Pantai}

a) Tampilkan form pantai

b) Jika pilih salah satu photo, maka akan menampilkan photo pantai Sulawesi Tenggara Jika pilihan kembali, maka akan kembali ke Menu Utama

\subsubsection{Algoritm Form Pilihan Panorama}

a) Tampilkan Form Panorama

b) Jika Pilih salah satu photo, maka akan menampilkan photo panorama Sulawesi Tenggara Jika pilihan kembali, maka akan kembali ke Menu Utama

\subsubsection{Algoritma Form Sejarah}

a) Tampilkan form Tapak Sejarah

b) Jika pilihan kembali, maka akan kembali ke Menu Utama

\subsubsection{Algoritma Form Penginapan}

a) Tampilkan Form Penginapan

b) Jika pilih salah satu photo, maka akan menampilkan photo penginapan Sulawesi Tenggara

c) Jika pilih kembali, maka akan kembali ke Menu Utama 
Jurnal Sistem Informasi dan Sistem Komputer, Vol. 5, No. 2, Juli 2020

pISSN: 2581-1614 eISSN: 2715-906X

\subsubsection{Algoritma Form Peta Lokasi}

a) Tampilkan Form Peta Lokasi

b) Jika pilihan kembali, maka akan kembali ke Menu Utama

\subsubsection{Algoritma Form Biodata Programmer}

a) Tampilkan Biodata Programmer

b) Jika pilihan kembali, maka akan kembali ke Menu Utama

\subsection{Tampilan Program}

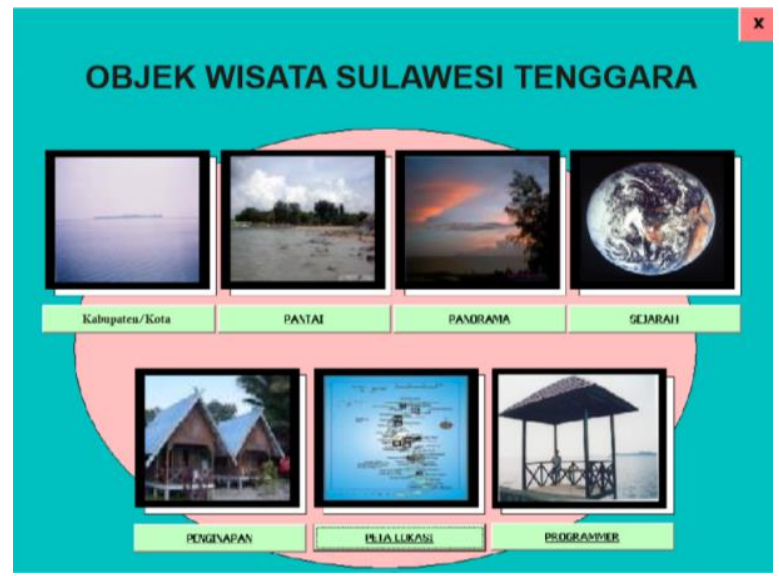

Gambar 5 : Tampilan Menu Utama

\subsection{Konfigurasi Komputer}

Setiap aplikasi yang ada dalam komputer mempunyai minimum konfigurasi komputernya masing-masing. Berikut adalah minimum konfigurasinya adalah :

1. Spesifikasi Software: Operating System Windows 7

Bahasa Pemrograman Visual Basic 6.0

2. Spesifikasi Hardware : Core i3 $4,2 \mathrm{GHz}$

\section{$\mathrm{RAM} 2 \mathrm{~Gb}$}

Vga Card $2 \mathrm{~Gb}$

Hardisk min. 320 Giga Byte

\section{Kesimpulan dan Saran}

\subsection{Kesimpulan}

Dengan adanya program aplikasi yang telah dibuat oleh penulis, maka diharapkan :

1. Seseorang semakin mendapat wawasan tentang Sulawesi Tenggara

2. Semakin banyak orang yang tertarik untuk mengunjungi obyek wisata Sulawesi Tenggara

3. Dengan adanya bersifat komputerisasi maka informasi yang didapat semakin mudah.

\subsection{Saran}

Aplikasi yang telah dibuat oleh penulis ini masih dapat dikembangkan, karena penulis menyadari bahwa program yang dibuat masih terdapat kekurangan.

Penulis menyarankan agar : 
Jurnal Sistem Informasi dan Sistem Komputer, Vol. 5, No. 2, Juli 2020

pISSN: 2581-1614 eISSN: 2715-906X

1. Aplikasi ini dapat dikembangkan dengan menambah informasi tentang obyek wisata lainnya yang terdapat di Sulawesi Tenggara seperti obyek wisata di Jawa Barat, Jawa Tengah dan lain-lain.

2. Dikembangkan dengan menambah suara dan gambar yang mewakili informasi obyek wisata itu sendiri.

\section{Daftar Pustaka}

[1] Departemen Pendidikan Nasional, Kamus Besar Bahasa Indonesia, Edisi Ketiga, PT. Gramedia, Jakarta, 2001.

[2] Davis Gordon B, Kerangka Dasar Sistem Informasi Manajemen Bagian I : Pengantar, cetakan ke sebelas, Penerbit Mc-Graw-Hill Kogakusha, Ltd, Tokyo, 1974.

[3] http:///www.tempatwisataunik.com, 28 April 2020, 15.30 WIB.

[4] Halvorson, Michael, Microsoft Visual Basic 6.0 Profesional Step by Step, Cetakan Pertama, PT. Elex Media Komputindo, Jakarta, 2000.

[5] Bambang Suwondo, Sejarah Kebangkitan Nasional Daerah Sulawesi Tenggara, Edisi I, 1984.

[6] Jogiyanto H.M., Analisa \& Desain Sistem Informasi Pendekatan Terstruktur, Edisi I, Andi Offset, Yogyakarta, 1991.

[7] Kurniadi, Adi, Pemrograman Visual Basic 6.0, Edisi Kedua, Elex Media Komputindo, Jakarta, 2000.

[8] M. Agus J. Alam, Belajar Sendiri Microsoft Visual Basic Versi 6.0, Cetakan Pertama, PT. Elex Media Komputindo, Jakarta 1999. 